\section{Comparative Approach to the Epidemiology of Wilm's Tumor}

\section{Abstract}

The background of the study was the need to compare the histopathology data pool of surgical specimens of Nigerian children of the Igbo ethnic group with the published parameters of Wilms tumor (WT). This was studied at a Reference Pathology Laboratory during a period of 30 years. Interesting results included the finding that all the patients presented with abdominal swelling. The peak age was between 24 and 59 months as in a series reported from a developed country. Other interesting parameters included the bilaterality of the lesion and metastasis to the lymph nodes. It is concluded that the histopathology data pool is an etiological method for investigating the epidemiology of Wilms tumor worldwide.

Keywords: Wilms tumor, Abdomen, Swelling, Childhood, Nigeria
Wilson I. B. Onuigbo

Department of Pathology, Medical Foundation and Clinic, 8 Nsukka Lane, Enugu 40001, Nigeria

\author{
Corresponding author: \\ Wilson I. B. Onuigbo \\ ” wilson.onuigbo@gmail.com \\ Department of Pathology, Medical \\ Foundation and Clinic, 8 Nsukka Lane, \\ Enugu 40001, Nigeria.
}

Tel: 2348037208680

Citation: Onuigbo WIB. Comparative Approach to the Epidemiology of Wilm's Tumor. Arch Cancer Res. 2016, 4:1.

\section{Introduction}

Dorland's Illustrated Medical Dictionary [1] defines Wilms tumor (WT) as "a rapidly developing malignant mixed tumour of the kidneys, made up of embryonal elements; it usually affects children before the fifth year, but may occur in the fetus and rarely in later life."

Concerning WT, the 2003 book, Cancer in Africa [2], published by the International Agency for Research on Cancer, World Health Organization, mentioned this tumor on but a single page in a Table in which its age-standardized (world) incidence per million was put at 2 for males and 3 for females in Nigeria, while the respective figures for England were 164 and 156. These figures raise the question as to the existence of epidemiologic differences with regard to this tumor between Nigeria and England.

Moreover, an English series [3] obtained from the Manchester Children's Tumour Registry during 29 years listed the age in months at the presentation of 151 patients. It is of interest, therefore, to compare these data with those on 58 Nigerian patients collected during 30 years.

\section{Materials and Methods}

From 20th February 1970 to 19th February 2000, the author headed a Regional Reference Laboratory based at Enugu, the capital of the then Eastern Region of Nigeria. This Laboratory has now served for long the Ibos or Igbos [4], one of the three main ethnic groups in this sprawling West African country.
Consultation was largely free but depended on the submission of adequate clinical notes with the formalin-fixed surgical specimens. The specimens were processed in the usual way and stained with haematoxylin and eosin. Duplicate reports were kept personally and have been analyzed for the present paper carefully. Comparison was made with the English series as well as with the world literature.

\section{Results}

As many as 55 of the 58 patients were treated at the University Teaching Hospital situated in the City of Enugu. The remaining three were handled in peripheral hospitals.

On comparing the age distribution (Table 1), it is apparent that one parameter stands out in both the local and the English series, namely, that the peak age is $24-59$ months. In fact, roughly $50 \%$ of cases clustered in that age group.

Males (36 cases) outnumbered females ( 22 cases) in the ratio of approximately 3:2.

Other parameters were obtained also. Firstly, all cases presented with abdominal swelling. Next in frequency was hematuria in 11 cases. Notable others were weight loss and fever, 10 each; and pain, 6 cases.

The right kidney was involved in 28 cases and the left numbered 24 cases; both sides were attacked once; and the side was not supplied in 5 instances. 
Table 1. Comparison of English and Nigerian WT Cases.

\begin{tabular}{|c|c|c|c|c|}
\hline Age (months) & \multicolumn{2}{|c|}{ England* } & \multicolumn{2}{c|}{ Nigeria } \\
\hline & $(\mathrm{No})$ & $(\%)$ & $(\mathrm{No})$ & $(\%)$ \\
\hline $1-2$ & 1 & 0.2 & 1 & 1.7 \\
\hline $3-5$ & 3 & 2.0 & 4 & 6.9 \\
\hline $6-11$ & 19 & 12.6 & 5 & 8.6 \\
\hline $12-23$ & 30 & 20.0 & 7 & 12.1 \\
\hline $24-59$ & 72 & 47.7 & 29 & 50.0 \\
\hline $60+$ & 26 & 17.2 & 12 & 20.7 \\
\hline Total & 151 & 100 & 58 & 100 \\
\hline
\end{tabular}

A single neonate presented with fever and hematuria. On his right side, the well encapsulated growth arose in the lower pole, which was enucleated while the left kidney appeared hypertrophied. However, within three weeks, the latter kidney mass enlarged and nephrectomy had to be performed for a fast growing WT.

Other notable findings were associations of the renal tumor with (a) angioma of the spleen in a girl aged $9 \frac{1}{2}$ years, (b) liver secondaries in a 6-year-old girl, and (c) replaced neighboring lymph nodes in 5 males and 3 females, i.e., $13.8 \%$ of the series.

\section{Discussion}

The most striking finding in this paper is the classic presentation of WT as an abdominal mass [5]. Also epidemiologically significant is the exactitude of the 24-59 months' peak age of incidence in both the English [3] and the present Nigerian series. French authors [6] stated that the peak incidence is between 1 and 5 years. Patently, this range is too wide in terms of age peak.

In the World Health Organization statistics [2], the Nigerian agestandardized incidence per million was put at 2 for males and 3 for females. However, the present series is the reverse, seeing that the male/female ratio is $3: 2$. Perhaps, the explanation is that the above figure came from the Western part of Nigeria where the main ethnic group is the Yoruba. Such a difference may be explained with future comparative studies in this developing country.

According to Rosai [5] and Losty [7], bilateral disease occurs in $5 \%-10 \%$ of cases. Our single cases constituted only $1.7 \%$. In this context, the figure provided by Kramer [8] for metachronous bilateral WT was $1.6 \%$.

In terms of the neonate, $0.8 \%$ of the patients registered on the US National WT studies from 1969 through April 1984 were 30 days old or less [9]. For comparison our single case is of the order of $1.7 \%$.
As regards lymph node metastasis, the French group [6] wrote that "the proximal lymph nodes are frequently spared." Our experience of lymphoid invasion amounted to $13.8 \%$, while the literature figure is $15 \%$ [5].

Both kidneys are reportedly equally affected [5]. Our figures of 28 (right) and 24 (left) with 5 undisclosed cases are not far from equality.

Some authors [5-7] have drawn attention to the association between WT and congenital anomalies such as aniridia, hemihypertrophy and congenital urinary tract defects. None of these appeared in the clinical notes supplied to me. The nearest lesion to these was the spleen whose examination revealed an angioma in the girl aged $9 \frac{1}{2}$ years. Curiously, it is cutaneous angioma that was mentioned in the literature as an anomaly [5].

Are there racial variations in the incidence of WT? One group [10] investigated it in relation to congenital anomalies and concluded that "there was a greater tendency for blacks to have bilateral tumours or a tumour associated anomaly, features characteristic of the hereditary form of Wilms' tumour." They found an excess of WT among black children, particularly black females. Accordingly, the preponderance of males in the Igbo cohort does not support their hypothesis.

Lastly, the thrust of this paper is the importance of analyzing the histopathology data pool which was recommended from the UK [11]. In this context, this contribution is entirely in line with such data pool. In other words, it is not geared to the type of research published from 8 Sub-Saharan Africa [12], including Kenya [13]. Moreover, it does not consider such a high flying parameter as racial disparities in peptide profiles [14].

\section{Conclusion}

The comparative approach to the epidemiology of WT using a histopathology data pool reveals that the peak age is from 24 to 59 months in both Nigerian and developed communities. Future research will be directed to clarifying any hitherto advanced hypothesis regarding various children suffering from this tumor worldwide.

\section{Acknowledgement}

Thanks are due to the doctors who took the trouble to send surgical specimens together with the requisite clinical details. 


\section{References}

1 (1973) Dorland's Illustrated Medical Dictionary, W.B. Saunders Company, (28 ${ }^{\text {th }}$ edn) Philadelphia.

2 (2003) Cancer in Africa. Epidemiology and prevention. WHO IARC Press, Lyon 390.

3 Marsden HB, Newton WA (1986) New look at mesoblastic nephroma. J Clin Pathol 39: 508-513.

4 Basden GT (1966) Niger Ibos. Frank Cass, London.

5 Rosai J (1996) Ackerman's Surgical Pathology. Mosby, St Louis ( $8^{\text {th }}$ edn) $1135-1140$.

6 Lemerle J, Donaldson SS (1973) Wilms' tumor: Current concepts in diagnosis, prognosis, and treatment. Paediatrician 1: 220-230.

7 Losty PD (1999) Recent advances. Paediatric surgery. Br Med J 318 1668-1672.

8 Kramer SA (1985) Paediatric urologic oncology. Urol Clin N Am 12: 31-42.
9 Hrabovsky EE, Otherson HB, Delorimer A (1986) Wilms' tumor in the neonate: A report from the National Wilms' Tumor Study. J Pediat Surg 21: 385-387.

10 Kramer S, Meadows AT, Jorrett P (1984) Racial variation in incidence of Wilms' tumor: Relationship to congenital anomalies. Med Pediat Oncol 12: 401-405.

11 Macartney JC, Rollaston TP, Codling BW (1980) Use of a histopathology data pool for epidemiological analysis. J Clin Pathol 33: 351-353.

12 Paintsil V, David H, Kambugu J (2015) The collaborative Wilms tumour Africa project; baseline evaluation of Wilms tumour treatment and outcome in eight institutes in sub-Saharan Africa. Eur J Cancer 51: 84-91.

13 Axt J, Abdallah F, Axt M (2013) Wilms tumor survival in Kenya. J Pediatr Surg 48: 1254-1262.

14 Libes JM, Seeley EH, Li M (2014) Race disparities in peptide profiles of North American and Kenyan Wilms tumor specimens. J Am Coll Surg, 218: 707-720. 